ISSN: 2638-5279

Volume 2, Issue 2, 2019, PP: 1-9

\title{
An in Vitro Model of Blast Induce Lung Injury using Shock Tube
}

\author{
Zhixin Liang ${ }^{\mathrm{a}}$, Zhaorui Zhang ${ }^{\mathrm{a}}$, Huaidong Li ${ }^{\mathrm{b}}$, Liang'an Chen ${ }^{\mathrm{a} *}$ \\ ${ }^{a}$ Department of Respiration, Chinese PLA General Hospital, China \\ ${ }^{b}$ Department of Respiratory Disease, The 88th Hospital of Chinese PLA, China \\ *chenliangan301@163.com
}

*Corresponding Author: Liang'an Chen, Department of Respiration, Chinese PLA General Hospital, No.28 Fuxing Road, Haidian District, Beijing 100853, China.

\section{Abstract}

The aim of this study was to establish an in vitro model of blast lung injury using shock tube. The study was performed from august of 2012 to May 2014 in PLA general hospital respiratory lab.A549 cells were exposed to $100 \pm 10$ kilopascal (Kpa) blast wave in a culture plate using a shock tube to mimic the in vitro model of blast lung injury. The morphological change and the Hoechst and PrI stain was observed by the light microscopic and electron microscopy. The apoptosis of cells was detected by flow cytometry. The mRNA expression of the inflammatory cytokines was measured by real-time PCR. Our results demonstrated that A549 cells showed increased cellular injury, cellular apoptosis, uptake of propidium iodide (PrI) and inflammatory cytokines mRNA expression after blast exposure. We conclude that we established a simple, reproducible model of blast lung injury.

Keywords: blast injury, cell injury, A549, in vitro, shock tube

\section{INTRODUCTION}

Blast lung injury is an increasing problem with high morbidity and mortality both in military and civilian practical. (1) Significant advantage have been made in our apprehension of blast lung injury by the use of animal models of blast injury. (2-4) The advantages of in vivo models are that they permit the study of the total organism's reaction to a multitude of complex variables and permit behavioral final result studies, which are perhaps the most powerful tool to assess functional final result and overall therapeutic efficacy. However disadvantages are also connected with the use of animal models of blast injury. In vivo studies do not allow easy assessment of effect of trauma on individual cell types. In vitro models of blast injury were powerful tools in investigating the cellular, biochemical, and molecular mechanisms of blast lung injury, discovering putative biomarkers, and targeted therapeutics. One of the major obstacles in studying the mechanisms of blast lung injury or screening drugs for defense is the lack of suitable in vitro model that can closely mimic the complex blast exposure. The intention of this study was to develop an easy reproducible in vitro model of blast lung injury for examining the morphologic biological and molecular consequences of blast induced injury on the human cell lines. It has been reported that results from invitro models of traumatic injury are having value for making prediction of the in-vivo results nearly $90 \%$. (5) High throughput in-vitro models of blast lung injury cost less and can use human cell lines and investigate the impact of blast on humans at the molecular level. Currently there exist a few animal models of blast lung injury using shock tubes to mimic battlefield blast exposures. $(6,7)$ Arun et al have successfully mimic the blast brain cellular injury in vitro using shock tube and found that cells were with decreased adenosine triphosphate levels, increased cellular injury, lactate 
An in Vitro Model of Blast Induce Lung Injury using Shock Tube

dehydrogenase release, and reactive oxygen species formation after blast exposure, $(8,9)$ but no in-vitro models of blast lung injury utilizing shock tube have been reported.

First of all we guessed whether we can establish an in vitro model of blast lung injury using human lung cell lines. Furthermore, we wished to develop a model that inflicts blast forces that are relevant to those which might occur in vivo. Thus a model of in vitro blast injury has been developed and characterized. A549 cells were human cell lines which were widely used as an in vitro model of acute lung injury. $(10,11)$ In our study, we exposed A549 cells to $100 \pm 10 \mathrm{Kpa}$ blast wave as a blast lung injury in vitro. The cell morphological change, cell viability, uptake of PrI, and inflammatory cytokines mRNA were observed. This in-vitro model may provide a platform for studying the biochemical and molecular mechanism and search drugs for protection the blast lung injury.

\section{Material ANd Methods}

\section{Shock Tulbe and Blast Exposure}

The study was performed from august of 2012 to May 2014 in PLA general hospital respiratory lab. It is a prospective study. The shock tube was a classical instrument used to replicate and direct blast waves in order to simulate actual explosions and their effects, usually on a smaller scale. $(12,13)$ More recently, shock tubes have been used in biomedical research to study how biological specimens are affected by blast waves. $(14,15)$ The shock tube used in our study was designed by state key lab of explosion and technology of Beijing institute of technology. Shock tube were used to produce peak pressures in the range of 100 to $300 \mathrm{kPa}$. The diagram of the shock tube include the firing pin, high pressure chamber, diaphragm and launching tube (Figure 1). The high pressure chamber was connected to a compressed air bottle. The air was transferred from the compressed air bottle to the high pressure chamber. When the pressure of the high chamber reached $5000 \mathrm{Kpa}$, the firing pin was launched and caused the diaphragm burst. the shock wave to propagate down the shock tube was launched. When the distance between the pressure detector and the shock tube was $60 \mathrm{~cm}$ the pressure detected by a pressure detector was $100 \pm 10 \mathrm{Kpa}$.

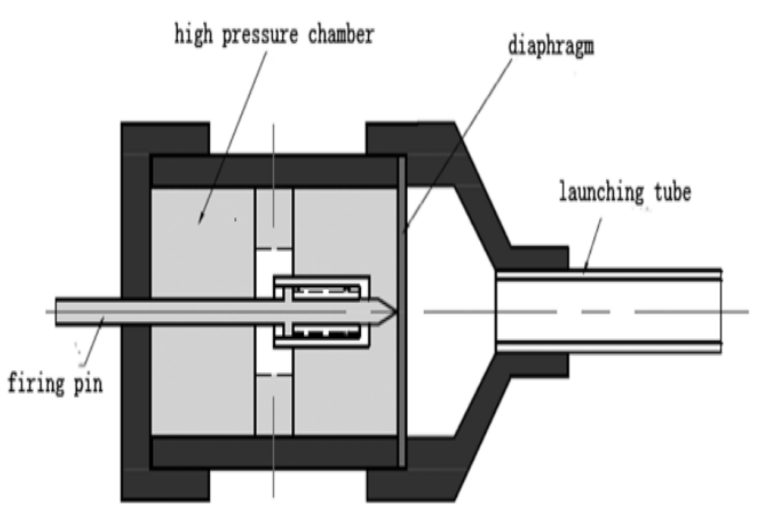

Figure 1. The diagram of the shock tube

\section{Cell Line and Culture Condition}

A549 cells (obtained from PLA general hospital respiratory lab), were grown in Dulbecco's Modified Eagle's Medium (DMEM)(Bioroc, China) with 10\% heat-inactivated fetal bovine serum (FBS), $100 \mathrm{U} / \mathrm{mL}$ penicillin, $100 \mathrm{mg} / \mathrm{mL}$ streptomycin in $10 \mathrm{~cm}$ dishes at $37^{\circ} \mathrm{C}$ in a humidified atmosphere of $5 \% \mathrm{CO}_{2}$. A549 cells were grown in tissue culture plates (corning USA) in a density of $4 \times 10^{5} / \mathrm{mL} 24 \mathrm{~h}$ before blast exposure. On the day before exposure to the blast wave, the cells were kept in the plate at $37^{\circ} \mathrm{C}$ in a humidified atmosphere of $5 \% \mathrm{CO}_{2}$. On the day of blast exposure, the medium was removed from the wells and fresh medium was added to the wells. The plates were sealed with sterile, gas permeable Mylar plate sealers (MP bio USA)and the edges of the plates and sealer were secured with sterile tape before blast exposure. (9)

Six well Plates(Corning.USA) containing the cells were secured in vertical position in front of the shock tube. (Figure 2). The distance between shock tube and the six well plate was $60 \mathrm{~cm}$ to insure the blast overpressure was $100 \pm 10 \mathrm{Kpa}$ which was detected by a pressure detector before. The plates containing cells were kept in the vertical position and subjected to $100 \pm 10 \mathrm{Kpa}$ blast overpressures. Immediately after blast exposure, the plates were returned to the $\mathrm{CO}_{2}$ incubator and incubated for indicated periods of time. Cells in the sham control group were handled similarly but were not exposed to blast for comparison. 
An in Vitro Model of Blast Induce Lung Injury using Shock Tube

\section{Light Microscopic Studies}

Morphological analysis of A549 was performed 6 hours post blast exposure. Morphological studies using the normal inverted microscope (Olympus, Japan) were carried out to observe the morphological changes of the A549 cells exposed to blast overpressure.

\section{Electron Microscopy}

Six hours following cell injury, each well in the plate was washed with PBS three times after which the cells were fixed a mixture consisting of $2 \%$ paraformaldehyde and 2\% glutaraldehyde. and then fixed with osmium tetroxide for $1 \mathrm{~h}$, stained with uranium acetate, embedded into epoxide resin. After sectioning into ultra-thin slices, the cells were stained with lead citrate and examined under transmission electron microscopy (H-7650, Hitachi, Japan).

\section{MTT Assay}

The A549 cells were seeded at a final concentration of $4 \times 10^{5} / \mathrm{mL}$ in a 96 -well culture plate. After different time intervals post blast(24h, 48h, 72h), cells were washed three times with Phosphate Buffered Saline (PBS) and $100 \mathrm{ml}$ fresh DMEM were added to each wells to conduct the cellular injury tests. Briefly, cells were washed with PBS solution and incubated again with $0.2 \mathrm{ml}$ fresh DMEM containing $0.5 \mathrm{mg} / \mathrm{ml}$ MTT (Sigma, USA) for $2 \mathrm{~h}$. The medium was then removed and MTT formazon was dissolved in $0.2 \mathrm{ml}$ imethylsulfoxide. The optical density was then determined at $490 \mathrm{~nm}$ using a micro plate reader (Dragon, USA).

\section{Hoechst and PrI Staining}

Six hours after blast exposure the cells were fixed and stained. In brief, cells were treated with PrI (Sigma, USA) and Hoechst (Sigma, USA) for $20 \mathrm{~min}$ at $4 \mathrm{C}$, then fixed and stained with $4 \%$ paraformaldehyde for $20 \mathrm{~min}$ at room temperature. Images were captured using Texas Red and UV filters (for PrI and Hoechst, respectively) on a fluorescence microscope(Olympus, Japan), PrI and Hoechst images were taken in five contiguous images, and were counted and averaged per well. All PrI and Hoechst cell counting were performed by one of the authors blinded to experimental conditions. Data are expressed as the ratio of PrI positive cells to total cell number (as determined by Hoechst staining of cell nuclei).

\section{Detection of Apoptosis by Flow Cytometry}

Six hours after blast exposure A549 cells were harvested, washed and resuspended with PBS. Apoptotic cells were determined with an fluorescein isothiocyanate (FITC) Annexin V Apoptosis Detection Kit (Keygen, China) according to the manufacturer's protocol. Briefly, the cells were washed and subsequently incubated for $15 \mathrm{~min}$ at room temperature in the dark in $100 \mu \mathrm{l}$ of $1 \times$ binding buffer containing $5 \mu \mathrm{l}$ of Annexin V-FITC and $5 \mu \mathrm{l}$ of PrI. Afterward, apoptosis was analyzed by fluorescence microscope and flow cytometer (BD, USA).

\section{Real-Time PCR for IL-1 $\beta, I L-6$ and Tumor Necrosis Factor Alpha (TNF- $\alpha$ )}

In brief, at different time intervals post blast $(2 \mathrm{~h}, 4 \mathrm{~h}$, $6 \mathrm{~h}, 8 \mathrm{~h}, 12 \mathrm{~h}, 24 \mathrm{~h}$ ), the medium was removed from each well and cells were collected. Total RNA was extracted using the trizol reagent (Takara, Japan) and reverse transcribed to cDNA using reverse transcription system (Takara, Japan) $1 \mu \mathrm{l}$ of cDNA was combined with primers and SYBR Green PCR Master Mix (Takara, Japan) to yield a final volume of $25 \mu \mathrm{l}$. The PCR conditions included 40 cycles of $95^{\circ} \mathrm{C}$ for 30 $\mathrm{s}, 60^{\circ} \mathrm{C}$ for $30 \mathrm{~s}$, and $95^{\circ} \mathrm{C}$ for $5 \mathrm{~min}$ on a StepOnePlus $\mathrm{s}^{\mathrm{TM}}$ Real-Time PCR System (BIO-RAD, USA). Threshold cycle (CT) values were determined by RT-PCR and normalized by the housekeeping gene $\beta$-actin. The relative level of indicated genes was calculated using the $2^{-\Delta \Delta \mathrm{Ct}}$ method. Primers are shown in Table 1.

The results were expressed as mean \pm standard deviation (SD). Statistical analysis was performed by t-test for overall significance. $\mathrm{p}<0.05$ was considered statistically significant. All analyses were carried out with the SPSS 20.0.

\section{RESUlTS}

\section{Morphologic Studies}

Cells in all areas appeared to be affected similarly. That is, cells in the center of the plates were not overtly different from cells closer to the edge of the plate. As shown in Figure 2 normal cultured A549 cells 
were regularly shaped and exhibited no cell swelling. The injured cells showed retracted or swollen. The connection of the cells were reduced and the gap between the cells became wider than sham control.

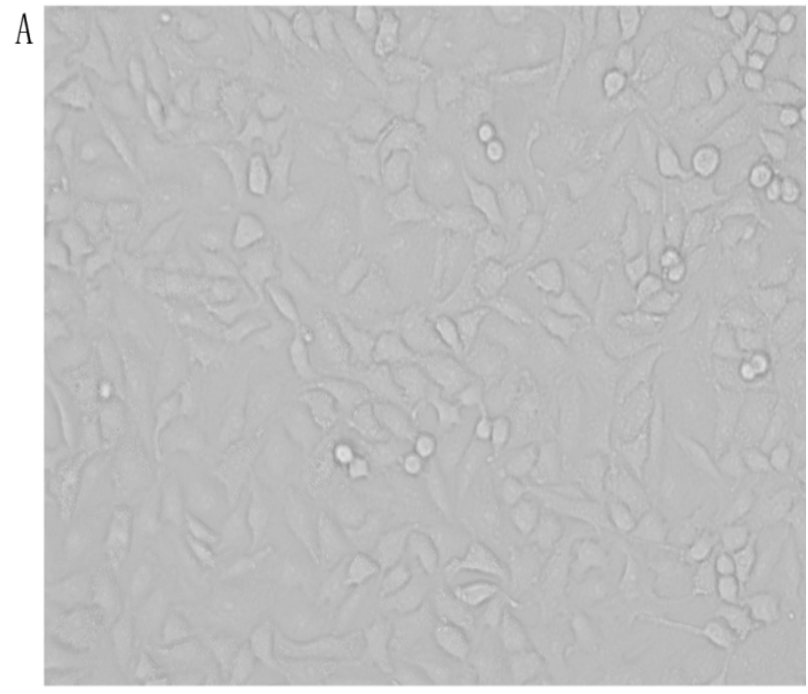

$\mathrm{B}$

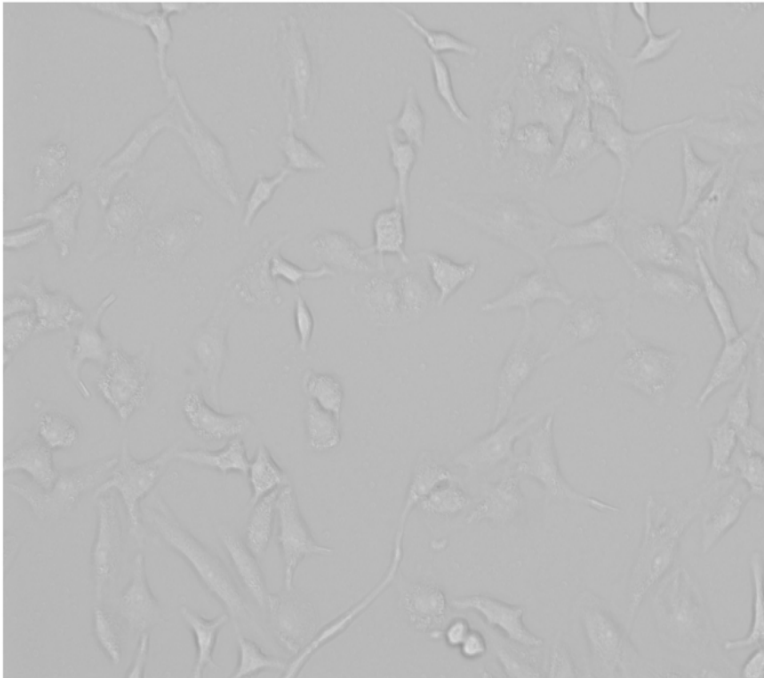

Figure 2. Light microscopic examination of normal and injured A549 cells six hours after injury. Figure A represent normal cells. Figure $\boldsymbol{B}$ represent injured cells. Magnification $=200 x$

The Electron microscopy revealed the ultrastructural detail of the A549 cells. The sham control A549 cell showed normal ultrastructural detail(Figure 3). Those A549 cells exposed to blast injury, on the other hand, showed evidence of structural change(Figure 4). With blast injury A549 cells showed structural abnormalities including cell shrinkage, chromatin condensation, nucleus pycnosis and endoplasmic hollowed.

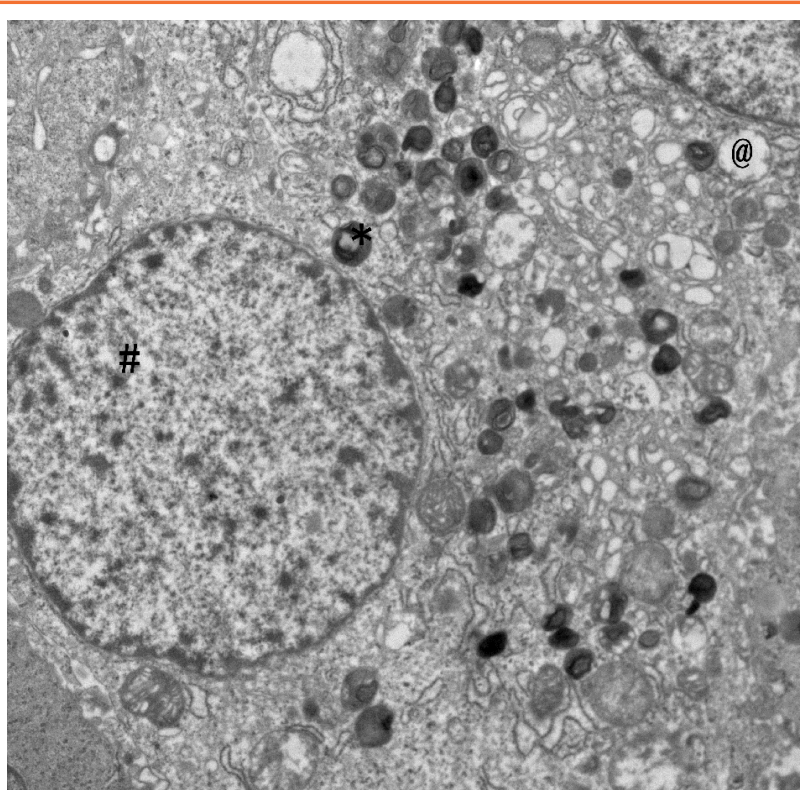

Figure 3. Normal A549 cell. Note that the A549 cell shows normal ultrastructural detail with normal cell nucleus plenty of organelles including lysosome ( $\left.{ }^{*}\right)$, Golgi body(@), endoplasmic reticulum and mitochondria. Magnification=10000x

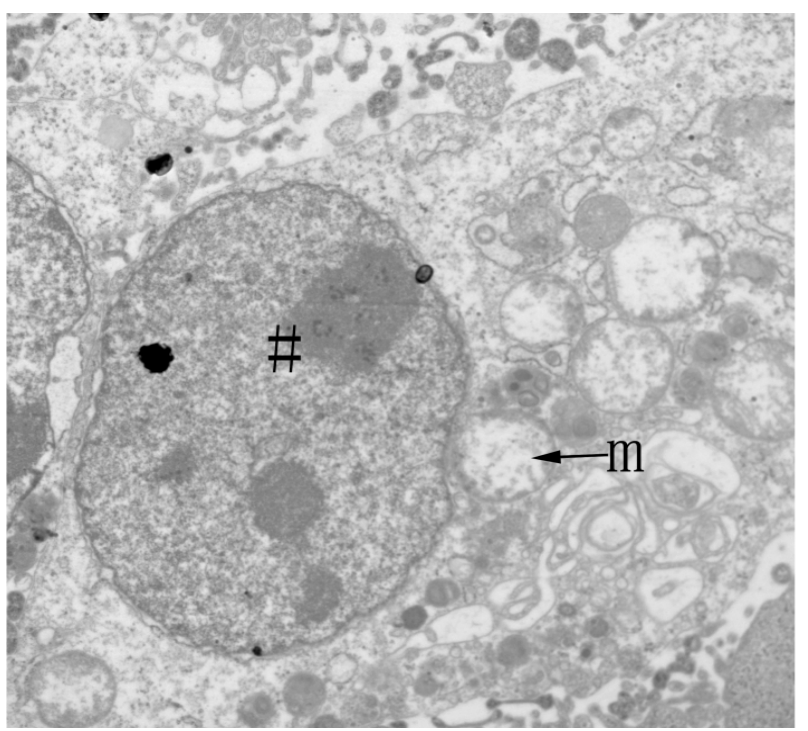

Figure 4. Injured A549 cell. Note that this A549 cell have many abnormal ultrastructural features including cell shrinkage, nucleus pycnosis(\#) and mitochondrial vacuolation $(m)$. Magnification $=10000 \times$

\section{MTT Assay}

A significant increase in cellular injury was observed in A549 cells after blast exposure. Figure 5 reflects the percentage of cell viability of the A549 cells after blast exposure at different intervals. MTT cell viability assay showed optical densities of sham control 
An in Vitro Model of Blast Induce Lung Injury using Shock Tube

cells and injury cells as $0.512 \pm 0.026 \quad 0.711 \pm 0.020$ $1.016 \pm 0.065$ and $0.379 \pm 0.065,0.628 \pm 0.068,0.914 \pm 0$ .029 , respectively, showing that the viability of cells in blast group were inhibited by the blast exposure $(\mathrm{p}<0.05)$. Time course of blast exposure on the A549 cells using MTT assay indicated that the maximum increase in cellular injury occurs at $24 \mathrm{~h}$ postblast exposure. The cells began to be repaired by $48 \mathrm{~h}$ post blast exposure and were almost $90 \%$ back to control levels by $72 \mathrm{~h}$. The results indicate that the injury induced blast occurred in the early times.

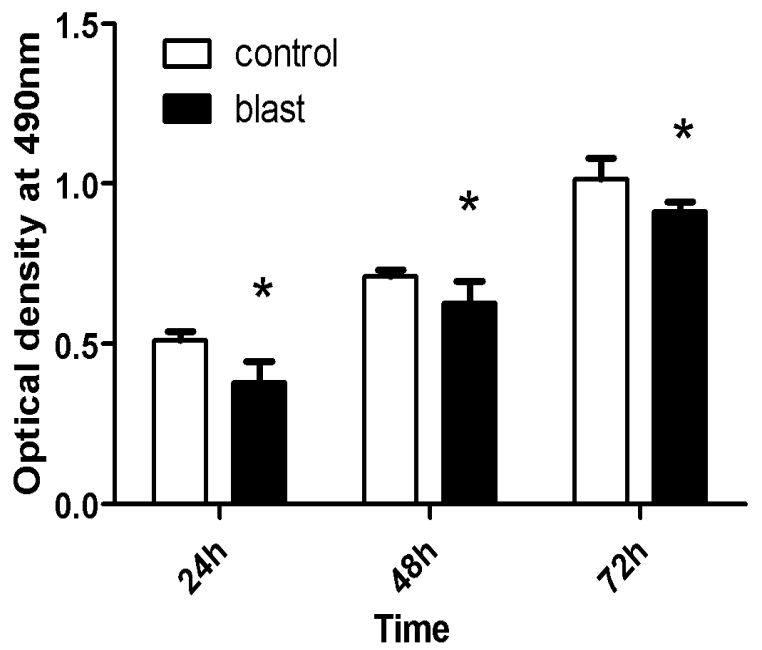

Figure 5. Time course of effect of blast exposure in A549 cells. MTT assay was carried out at 24, 48, and 72 h post exposure. Values of blast-exposed cells at each time point were compared with those of control cells ( $n=6,{ }^{*} p<0.05$ vs control group).

\section{Blast Injury Increases PrI Uptake in A549 Cells}

Injury was assessed by measuring the uptake of PrI as previous described ${ }^{[17]}$. Hoechst labels the nuclei of all cells, whereas PrI is normally excluded from intact cell membranes. In uninjured control cells, there was little PrI staining, indicating that most cells were healthy and viable, with intact cell membranes(Figure $6 \mathrm{C}$ and D). If membranes are damaged, PrI will enter cells and stain the nucleus, resulting in a bright red fluorescence, but is rapidly taken up by cells with damaged membranes (Figure 6A and B). PrI was excluded from almost all control cells and thus few or no fluorescent red nuclei were observed. However, $2 \mathrm{~h}$ after blast injury, the amount of PrI staining cells were increasing, indicating that the cells were injuried with unintact cell membranes similar in early times. PrI uptake decreased with time post-injury, but remained significantly elevated through $12 \mathrm{~h}$ after blast exposure. However PrI uptake returned to control levels after 24h blast injury (Figure 7).

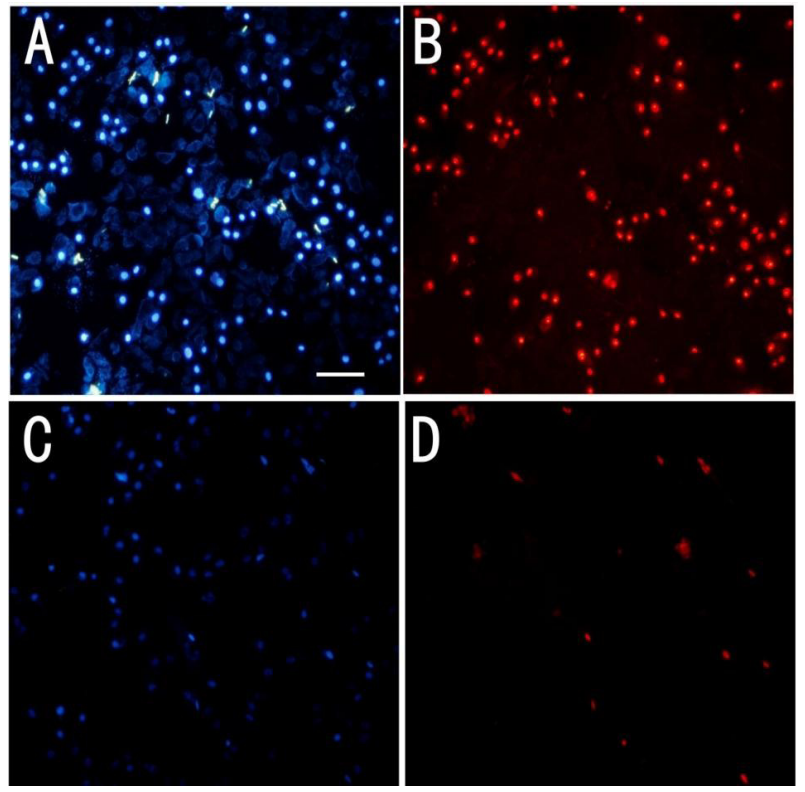

Figure 6. Effect of blast wave on A549 cultures. (A) Cells stained with hoechst in blast group. (B) Cells stained with PrI in blast group. (C) Cells stained with Hoechst in control group. (D) Cells stained with PrI in control group.

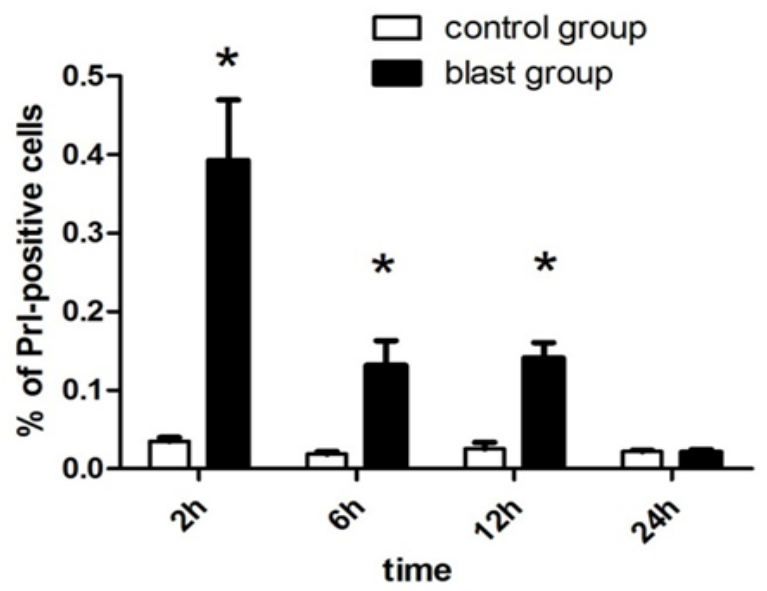

Figure 7. PrI uptake percentage. Data are shown at 2 $h, 6 h, 12 h$ and $24 h$ post-injury (means \pm SE values).* $p<0.05$ vs control group

\section{Assessment of Apoptosis by Annexin V-FITC}

Six h after blast exposure, the cells were harvested, and apoptosis was examined with flow-cytometry after Annexin V-PI double staining(keygen, China). 
An in Vitro Model of Blast Induce Lung Injury using Shock Tube

Viable cells exhibit AnnexinV (-)/PI (-); early apoptotic cells exhibit Annexin (+)/ PI(-); late apoptotic cells or necrotic cells exhibit AnnexinV (+)/PI (+). The necrotic cells lost cell membrane integrity that permits PI entry. Quantitative analysis using Annexin V/PI assay further showed that the proportion of early and late stage apoptotic cells of the blast group increased significantly compared with that of the control group $(\mathrm{p}<0.05)$. (Figure 8)

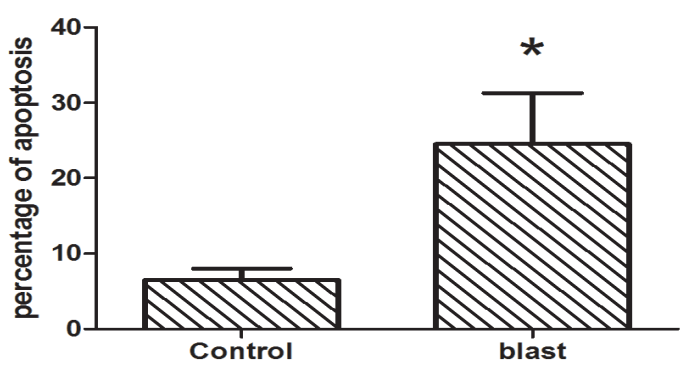

Figure 8. The proportion of apoptosis of A549 cells after 6 h blast exposure. Note: * vs control $p<0.05$

\section{IL-1 $\beta$, IL- 6 and TNF- $\alpha$ mRNA Expression}

IL-1 $\beta$, IL- 6 and TNF- $\alpha$ release after injury was also assessed since it is a biochemical marker of injury and has been used to document cell injury indeed,for example, by lipopolysaccharide stimulation in culture $^{[18]}$. The results shown in Figure 9-11 indicate that blast exposure to A549 cells significant increase in the inflammatory factors IL-1 $\beta$, IL- 6 and TNF- $\alpha$ mRNA expression. $(\mathrm{p}<0.05)$. All the inflammatory factors mRNA expression began to increase in $2 \mathrm{~h}$ after blast exposure and accumulate at their peak $6 \mathrm{~h}$ after blast exposure. In the 8 hours after blast, the cytokines began to decline and returned to normal in the $24 \mathrm{~h}$ post blast.

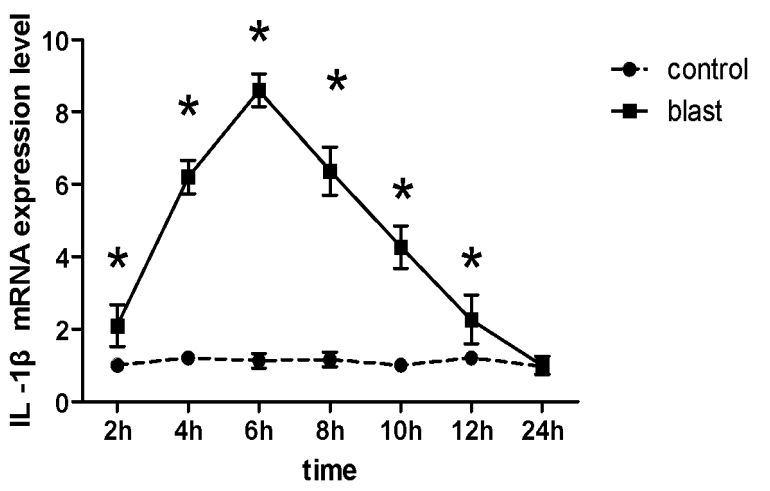

Figure 9. Change of $I L-1 \beta m R N A$ expression. Note: * $p<0.05$ vs control, $n=3$

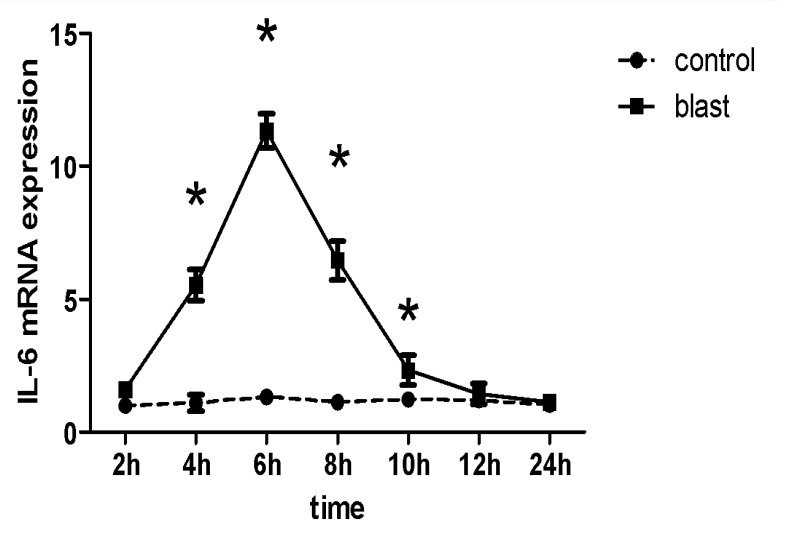

Figure 10. Change of IL-6 mRNA expression. Note: * $p<0.05$ vs control, $n=3$.

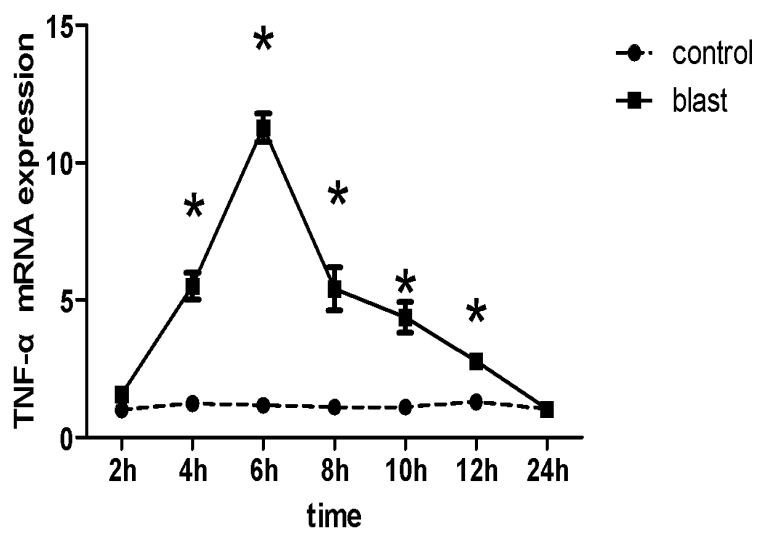

Figure 11. Change of TNF- $\alpha$ mRNA expression. Note: * $p<0.05$ vs control, $n=3$

\section{Discussion}

It is still unclear that the mechanics and therapeutic approach of blast injury, so it is necessary to study the in vitro model of blast injury. In-vitro models offer unique opportunity to study effects of blast overpressure on different type cells in the lung or combination of cells to unravel the pathological and protective roles. The goal of this study was to develop a simple, reproducible in vitro model of blast lung injury.

Our results demonstrate that we can develop an easy reproducible in-vitro model of blast lung injury using lung epithelial cells an an air-driven shock tube. This is the first report demonstrating an in vitro model of blast lung injury using human epithelial cells and shock tube.

For rapid development and assessment of the injury model PrI proved to be the most suitable indicator for injury. This fluorescent dye has a molecular weight 
An in Vitro Model of Blast Induce Lung Injury using Shock Tube

of 668 atomic mass unit. Cells with normal intact membranes exclude the dye, while cells with damaged membranes can not exclude the dye and it bind to the nucleus. Our experiments indicate that the dye, more properly, identifies "injured " cells, which may or may not have the ability to repair themselves and regain their capacity to exclude PrI. Therefore,PrI appear to be a marker of injury since the cells regained their capacity to exclude PI. Blast injury on its own increased uptake of PrI in A549 cells. Cell injury was assessed by measuring the uptake of PrI described by previous study. (16) Our data showed that blast exposure can significantly increase the uptake of PrI in the early times, and after blast exposure PrI uptake decreased with time post-injury, and returned normal level 24 $\mathrm{h}$ after blast exposure. Our results were similar to previous studies, which showed that the uptake of PrI increasing using the stretch injury mode in culture cells in vitro. $(17,18)$

It has been approved that blast overpressure could induce the pulmonary epithelial cell apoptosis and increase of inflammatory factors. $(3,19)$ Alveolar type 2 cell apoptosis is an important mechanism during lung inflammation, lung injury, and regeneration. Alveolar type 2 cell apoptosis has been described to occur after blast lung injury in rats and may contribute to the pathogenesis and resolution of acute respiratory distress syndrome (ARDS). $(3,20)$ Our results revealed that blast overpressure can significant increased the apoptosis and decrease the variability of the A549 cell indicating that blast exposure causes significant cellular injury in an time dependent manner.

Cytokines have been shown to mediate the response of the pulmonary system to chest trauma, including the development of acute respiratory distress syndrome. $(6,7)$ Numbers reports exist of in vitro cytokine production by culture human lung cell following a chemical infectious insult. (21-23) It has been reported that extensive release of cytokines interleukin-1 (IL-1), interleukin-6(IL-6), monocyte chemotactic peptide-1 (MCP-1), and macrophage inflammatory protein-2 (MIP-2) was observed in BAL fluid and blood plasma during $24 \mathrm{~h}$ post exposure of shock wave in a rat model. (24) Studies has shown that IL-1 $\beta$ and IL- 6 are the key trigger inflammatory factors in the mechanics of acute respiratory distress syndrome(ARDS). (25) We demonstrate that blast exposure of A549 cells result in the increase of IL-1 $\beta$, IL- 6 and TNF- $\alpha$ mRNA expression. The inflammatory cytokines mRNA expression increased and all accumulate to their climax $6 \mathrm{~h}$ post blast exposure and returned to normal level $24 \mathrm{~h}$ after blast exposure. Our results were similar to the previous studies in vivo. Chavko $M$ reported that after exposure to 150 Kpa blast wave the lung inflammatory chemokine mRNA expression of rats; macrophage inflammatory protein-1, monocyte chemotactic peptide-1, and cytokine-induced neutrophil chemoattractant-1 were increased and get climax after $48 \mathrm{~h}$ post blast exposure (7). Perl M et al reported that response to blunt chest trauma followed by sepsis as well as after sepsis alone, a significant local and systemic inflammatory response with increased cytokines (including IL$1 \beta$,IL- 6 and TNF- $\alpha$ )in lung and plasma was observed in rat. (20) Accumulation of inflammation factors is a common mechanism of damage in many models of acute lung injury in vitro and in vivo. $(7,12)$ Augmented early inflammatory response, with accumulation of inflammatory mediators and chemotaxis, as well as free reactive reactions causing oxidative damage play an important role in the pathogenesis of blast lung injury. This in turn lead to damage of epithelial cell damage and the acute respiratory distress syndrome. Alveolar epithelial cells are often targeted by inflammatory and infectious agents and they participate in the initiation and progression of acute lung injury. Animal studies showed that blast lung injury induced apoptosis in alveolar epithelial cells and increase of inflammatory factors such as IL-1 $\beta$. (3)

We also observed morphological features characteristic rounding of A549 cells after blast exposure for compared with sham controls. Unlike the PrI and inflammatory factors studies that examined cells at various time periods after, the current light and electron microscopy studies were confined to cell in the 6 hour post injury period. These light and electron micrographic studies showed a range of damage to the A549 cells. Some cells were swollen and the amount of cells were reduced. Some cells visualized by light microscopy became retracted, suggesting cytoskeletal disruption. The electron microscopy 
An in Vitro Model of Blast Induce Lung Injury using Shock Tube

revealed the ultrastructure change of cells exposed to blast overpressure. The mitochondrial vacuolation and cell shrinkage suggesting the certain cell function such as oxidative phosphorylation and energy charge could be compromised, however, this remains to be ascertained. The cell nucleus pycnosis indicating that function of the cell nucleus may be compromised and may have relationship with the apoptosis of the cell. It is anticipated that the future studies examining the ultrastructural fate of these cells over a more prolonged post blast time will provide more information concerning recovery of the injured cells.

In summary, our study develop a new in vitro model of blast lung injury indicate that blast exposure lead to inhibition of cell proliferation and increase of apoptosis and inflammatory cytokines. However, no one model can completely closely mimic the complex primary, secondary, tertiary, and quaternary components of blast exposure. More detailed studies are wanted to reveal the precise mechanics of blast lung injury.

\section{Funding}

This study was supported by the military twelfth fiveyear key project of china(BWS11J057).

\section{REFERENCES}

[1] Nelson TJ, Wall DB, Stedje-Larsen ET, Clark RT, Chambers LW and Bohman HR: Predictors of mortality in close proximity blast injuries during Operation Iraqi Freedom. J Am Coll Surg 202: 418-422, 2006.

[2] Liener UC, Knoferl MW, Strater J, et al: Induction of apoptosis following blunt chest trauma. Shock 20: 511-516, 2003.

[3] Seitz DH, Perl M, Mangold S, et al: Pulmonary contusion induces alveolar type 2 epithelial cell apoptosis: role of alveolar macrophages and neutrophils. Shock 30: 537-544, 2008.

[4] Chavko M, Adeeb S, Ahlers ST and McCarron RM: Attenuation of pulmonary inflammation after exposure to blast overpressure by $\mathrm{N}$-acetylcysteine amide. Shock 32: 325-331, 2009.

[5] Morrison B 3rd, Elkin BS, Dolle JP and Yarmush ML: In vitro models of traumatic brain injury. Annu Rev Biomed Eng 13: 91-126, 2011.
[6] Knoferl MW, Liener UC, Seitz DH, et al: Cardiopulmonary, histological, and inflammatory alterations after lung contusion in a novel mouse model of blunt chest trauma. Shock 19: 519-525, 2003.

[7] Chavko M, Adeeb S, Ahlers ST and McCarron RM: Attenuation of pulmonary inflammation after exposure to blast overpressure by N-acetylcysteine amide. Shock 32: 325-331, 2009.

[8] Arun P, Spadaro J, John J, Gharavi RB, Bentley TB and Nambiar MP: Studies on blast traumatic brain injury using in-vitro model with shock tube. Neuroreport 22: 379-384, 2011.

[9] Arun P, Abu-Taleb R, Valiyaveettil M, Wang Y, Long JB and Nambiar MP: Transient changes in neuronal cell membrane permeability after blast exposure. Neuroreport 23: 342-346, 2012.

[10] Li B, Dong C, Wang G, Zheng H, Wang X and Bai C: Pulmonary epithelial CCR3 promotes LPSinduced lung inflammation by mediating release of IL-8. J Cell Physiol 226: 2398-2405, 2011.

[11] Nishio K, Horie M, Akazawa Y, et al: Attenuation of lipopolysaccharide (LPS)-induced cytotoxicity by tocopherols and tocotrienols. Redox Biol 1: 97-103, 2013.

[12] Chavko M, Prusaczyk WK and McCarron RM: Lung injury and recovery after exposure to blast overpressure. J Trauma 61: 933-942, 2006.

[13] Bass CR, Meyerhoff KP, Damon AM, Bellizzi AM, Salzar RS and Rafaels KA: Drosophila melanogaster larvae as a model for blast lung injury. J Trauma 69: 179-184, 2010.

[14] Chavko M, Koller WA, Prusaczyk WK and McCarron RM: Measurement of blast wave by a miniature fiber optic pressure transducer in the rat brain. J Neurosci Methods 159: 277-281, 2007.

[15] Cernak I: The importance of systemic response in the pathobiology of blast-induced neurotrauma. Front Neurol 1: 151, 2010. 
An in Vitro Model of Blast Induce Lung Injury using Shock Tube

[16] Ellis EF, McKinney JS, Willoughby KA, Liang S and Povlishock JT: A new model for rapid stretchinduced injury of cells in culture: characterization of the model using astrocytes. J Neurotrauma 12: 325-339, 1995.

[17] McKinney JS, Willoughby KA, Liang S and Ellis EF: Stretch-induced injury of cultured neuronal, glial, and endothelial cells. Effect of polyethylene glycol-conjugated superoxide dismutase. Stroke 27: 934-940, 1996.

[18] Weber JT, Rzigalinski BA, Willoughby KA, Moore SF and Ellis EF: Alterations in calcium-mediated signal transduction after traumatic injury of cortical neurons. Cell Calcium 26: 289-299, 1999.

[19] Seitz DH, Froba JS, Niesler U, et al: Inhaled hydrogen sulfide induces suspended animation, but does not alter the inflammatory response after blunt chest trauma. Shock 37: 197-204, 2012.

[20] Perl M, Hohmann C, Denk S, et al: Role of activated neutrophils in chest trauma-induced septic acute lung injury. Shock 38: 98-106, 2012.
[21] Koch T, Ragaller M, Haufe D, et al: Perfluorohexane attenuates proinflammatory and procoagulatory response of activated monocytes and alveolar macrophages. Anesthesiology 94: 101-109, 2001.

[22] Nakstad B, Wolfson MR, Shaffer TH, et al: Perfluorochemical liquids modulate cellmediated inflammatory responses. Crit Care Med 29: 1731-1737, 2001.

[23] Chang H, Kuo FC, Lai YS and Chou TC: Inhibition of inflammatory responses by FC-77, a perfluorochemical, in lipopolysaccharide-treated RAW 264.7 macrophages. Intensive Care Med 31: 977-984, 2005.

[24] Gorbunov NV, McFaul SJ, Januszkiewicz A and Atkins JL: Pro-inflammatory alterations and status of blood plasma iron in a model of blastinduced lung trauma. Int J Immunopathol Pharmacol 18: 547-556, 2005.

[25] Buttenschoen K, Kornmann M, Berger D, Leder G, Beger HG and Vasilescu C: Endotoxemia and endotoxin tolerance in patients with ARDS. Langenbecks Arch Surg 393: 473-478, 2008.

Citation: Zhixin Liang, Zhaorui Zhang, Huaidong Li, Liang'an Chen. An in Vitro Model of Blast Induce Lung Injury using Shock Tube. Open Access Journal of Internal Medicine. 2019; 2(2): 1-9.

Copyright: (C) 2019 Zhixin Liang, Zhaorui Zhang, Huaidong Li, Liang'an Chen. This is an open access article distributed under the Creative Commons Attribution License, which permits unrestricted use, distribution, and reproduction in any medium, provided the original work is properly cited. 